J. Lake Sci. (湖泊科学), 2011, 23(2): 203-208

http: //www. jlakes. org. E-mail : jlakes@niglas.ac.cn

(C) 2011 by Journal of Lake Sciences

\title{
不同湿地植物对污水中氮磷去除的贡献”
}

\author{
崔丽娟 ${ }^{1}$, 李 伟 ${ }^{1}$, 张曼能 ${ }^{1}$, 赵玉辉 ${ }^{1}$, 王义飞 ${ }^{1}$, 赵欣胜 ${ }^{1}$, 商晓静 ${ }^{2}$ \\ (1: 中国林业科学研究院湿地研究所, 北京 100091) \\ (2: 翠湖国家城市湿地公园, 北京 100194)
}

摘 要: 选择 5 种湿地植物 (芦苇、东方香蒲、菖蒲、荠白、㚜尾) 和 1 种喜湿灌木 (蒿柳), 研究重度富营养化水体中植物 的生长特性和氮磷去除效果. 研究发现, 所选用的 6 种植物在实验池中均生长良好, 稳定生长 $105 \mathrm{~d}$ 以后, 各种植物的总生 物量在 $424-1772 \mathrm{~g} / \mathrm{m}^{2}$ 之间, 除了香蒲的地上地下生物量比 $(\mathrm{A} / \mathrm{U})$ 达到 3.23 外, 其它的比值在 $0.63-1.49$ 之间. 6 种植 物地上部 $\mathrm{N}$ 和 $\mathrm{P}$ 浓度分别在 $13.12-28.83 \mathrm{mg} / \mathrm{g}$ 及 $1.55-3.77 \mathrm{mg} / \mathrm{g}$ 之间, 地下部 $\mathrm{N}$ 和 $\mathrm{P}$ 浓度在 $7.76-15.60 \mathrm{mg} / \mathrm{g}$ 及 $1.70-2.71 \mathrm{mg} / \mathrm{g}$ 之间, 大部分植物地上部 $\mathrm{N}$ 和 $\mathrm{P}$ 的浓度大于地下部. 6 种植物平均氮、磷积累量分别为 $20.60 \mathrm{~g} / \mathrm{m}^{2}$ 和 $3.08 \mathrm{~g} / \mathrm{m}^{2}$, 其中地上部平均氮、磷积累量分别占 $66.60 \%$ 和 $58.22 \%$. 不同植物篮选池对不同污染物的净化效果有差异, 感 尾池对 TN 的净化效果最好, 芦苇池对 TP 的净化效果最好. 植物的氮、磷积累量与浓度及生物量之间均存在显著相关.

关键词: 湿地植物;污水;生物量;积累量;净化效果

\section{Different wetland plant roles of removing nitrogen and phosphorus on sewage water}

\author{
CUI Lijuan ${ }^{1}$, LI Wei ${ }^{1}$, ZHANG Manyin $^{1}$, ZHAO Yuhui ${ }^{1}$, WANG Yifei ${ }^{1}$, ZHAO Xinsheng $^{1}$ \& SHANG Xiaojing ${ }^{2}$ \\ (1: Institute of Wetland Research, Chinese Academy of Forestry, Beijing 100091, P. R. China) \\ (2: Cuihu National Urban Wetland Park, Beijing 100194, P. R. China)
}

\begin{abstract}
Five kinds of wetland plants, including reed (Phragmites australis), oriental cattail (Typha orientalis), calamus (Zizania aquatica), wildrice stem (Acorus calamus), Iris (Iris tenuifolia), and one kind of shrub of willow (Salix viminalis) were selected to study the growth characteristics of plants and the role of removing nitrogen and phosphorus in severe eutrophic waters. The study showed that the six kinds of plants in experiments grew well and steadily. After 105 days, the total biomass ranged from 424 to $1772 \mathrm{~g} / \mathrm{m}^{2}$. Ratios of most plant biomass above/below ground ( $\mathrm{A} / \mathrm{U}$ ) varied between 0.63 and 1.49 , except for oriental cattail ( $\mathrm{A} / \mathrm{U}: 3.23$ ). Concentrations of nitrogen and phosphorus in the biomass of above ground ranged from 13.12 to $28.83 \mathrm{mg} / \mathrm{g}$ and from 1.55 to $3.77 \mathrm{mg} / \mathrm{g}$, respectively. Concentrations of nitrogen and phosphorus in the biomass below ground ranged from 7.76 to $15.60 \mathrm{mg} / \mathrm{g}$ and from 1.70 to $2.71 \mathrm{mg} / \mathrm{g}$, respectively. The concentrations of nitrogen and phosphorus between above and below ground biomass differed significantly. The average plant accumulations of nitrogen and phosphorus were $20.60 \mathrm{~g} / \mathrm{m}^{2}$ and $3.08 \mathrm{~g} / \mathrm{m}^{2}$, which the above ground accounted for $66.60 \%$ and $58.22 \%$, respectively. Purification effect of the plants on different pollutants was different. The best purification effects for TN in Iris and TP in reed were found. Plant accumulations of nitrogen and phosphorus displayed significantly positive linear correlation with plant biomass and concentrations of nitrogen and phosphorus.
\end{abstract}

Keywords: Wetland plant; waste water; biomass; accumulation; purification efficiency

湿地植物在污水净化等方面起着重要的作用 ${ }^{[1-2]}$. 湿地植物种类繁多, 且具有较强的地域性, 不同湿地 植物对污染物质的去除能力有较大的差异 ${ }^{[3-5]}$. 因此,篮选适合生长且净化能力较强的湿地植物用于湿地水 质净化和水环境修复具有重要的理论和现实意义. 目前针对湿地植物污水净化效果的研究很多,国内外学 者利用芦苇、香蒲和艾白等湿地植物来构建人工湿地处理污水的研究已有许多报道, 湿地植物在人工湿地

* 北京市科技计划重大项目“北京市湿地生态系统保护与恢复关键技术研究和示范” ( D08040600580000) 和国家科 技支撑计划“十一五”项目“湿地生态系统保护与恢复技术试验示范” (2006BAD03A19) 联合资助. 2010-02-24 收稿;2010-09-22 收修改稿. 崔丽娟,女,1968 年生,研究员;E-mail:1kyclj@ 126. com. 
中发挥了十分重要的作用, 但这些植物多为草本植物, 而利用乔木、灌木作为人工湿地植物的报道甚少 ${ }^{[6-10]}$. 本研究设于北京地区野外自然条件下, 选择了 5 种湿地植物和 1 种喜湿灌木研究不同植物单种的净化效果 以及在重度富营养化水体中的生长特性和氮磷去除作用, 旨在篮选出净化能力较强的湿地植物, 以期为北 京地区污染湿地水质净化和退化湿地恢复提供科学依据.

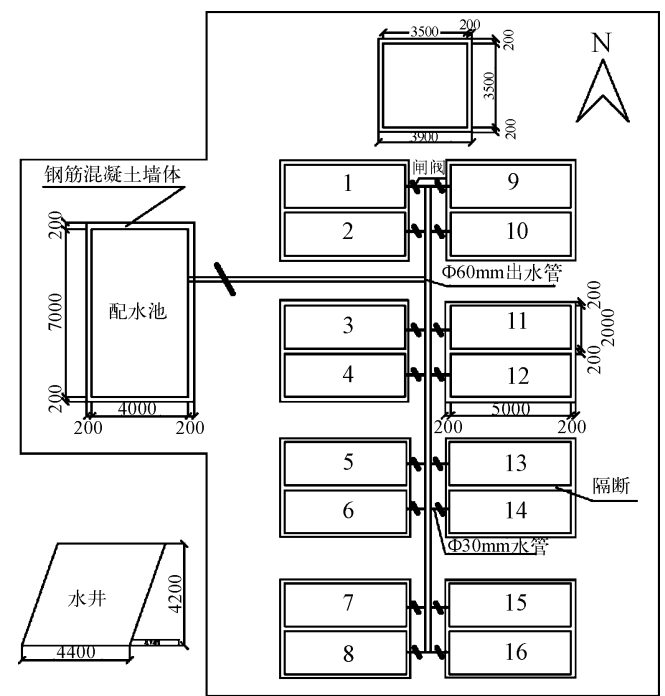

图 1 湿地植物篎选池平面图 (单位: $\mathrm{mm}$ )

Fig. 1 Map of filter pool of wetland plants

\section{1 材料和方法}

\section{1 实验池构建和实验运行}

实验地位于北京市西北部的延庆县康庄镇军营村 西, 占地面积约 $1000 \mathrm{~m}^{2}$. 该地海拔约 $500 \mathrm{~m}$, 年均气温 $8^{\circ} \mathrm{C}$, 年均降水量 $493 \mathrm{~mm}$; 地处温带与中温带、半干早与 半湿润带的过渡带, 属大陆性季风气候. 实验池由配水 池、湿地植物篎选池和出水池三部分组成, 其中湿地植 物笁选池 16 个 (单池长: 宽: 高 $=500 \mathrm{~cm}: 200 \mathrm{~cm}$ : $85 \mathrm{~cm})$, 配水池和出水池各一个. 各湿地植物篎选池内 填充相同的基质, 从下至上依次为砾石 $15 \mathrm{~cm}$ (粒径 $5-$ $8 \mathrm{~cm}$ )、豆石 $20 \mathrm{~cm}$ (粒径 $0.5-1 \mathrm{~cm}$ ) 和沙壤土 $10 \mathrm{~cm}$ (过 篮 $2 \mathrm{~mm}$ ).

2009 年 5 月 5 日,采集官厅水库库滨带大小较均 匀的 6 种实验植物, 其中挺水植物 5 种, 即禾本科芦苇 属的芦苇 (Phragmites australis)、香蒲科香蒲属的东方 香蒲 (Typha orientalis Presl. )、禾本科菰属的艾白 (Zizania aquatica)、天南星科菖蒲属的菖蒲 (Acorus calamus Linn.)、茑尾科荅尾属的荅尾 (Iris tenuifolia); 湿生灌木

1 种, 即杨柳科柳属的蒿柳 (Salix viminalis L.) , 分别栽种到植物笁选池 $1-6$ 中, 种植密度为 4 棵 $/ \mathrm{m}^{2}$. 采用 地下水预培养 1 个月. 2009 年 6 月 5 日, 将污水经配水池缓慢放人植物笁选池 (水深 $35 \mathrm{~cm}$ ). 由于水流通过 水管均匀流人植物笁选池, 污水通过布设在植物笁选池的布水管流人, 缓慢向下渗滤, 放水 $12 \mathrm{~h}$ 后, 停止注 水. 因此整个植物笁选池具有相似的水力负荷, 从而保证湿地植物具有相似的生长环境. 经过植物笁选池处 理后的水从植物笁选池底部排出. 实验用水取自延庆县饲养动物粪水污水, 初始水质起始浓度总氮 ( TN) 为 $32.13-78.21 \mathrm{mg} / \mathrm{L}$, 总磷 $(\mathrm{TP})$ 为 $7.74-21.76 \mathrm{mg} / \mathrm{L}$.

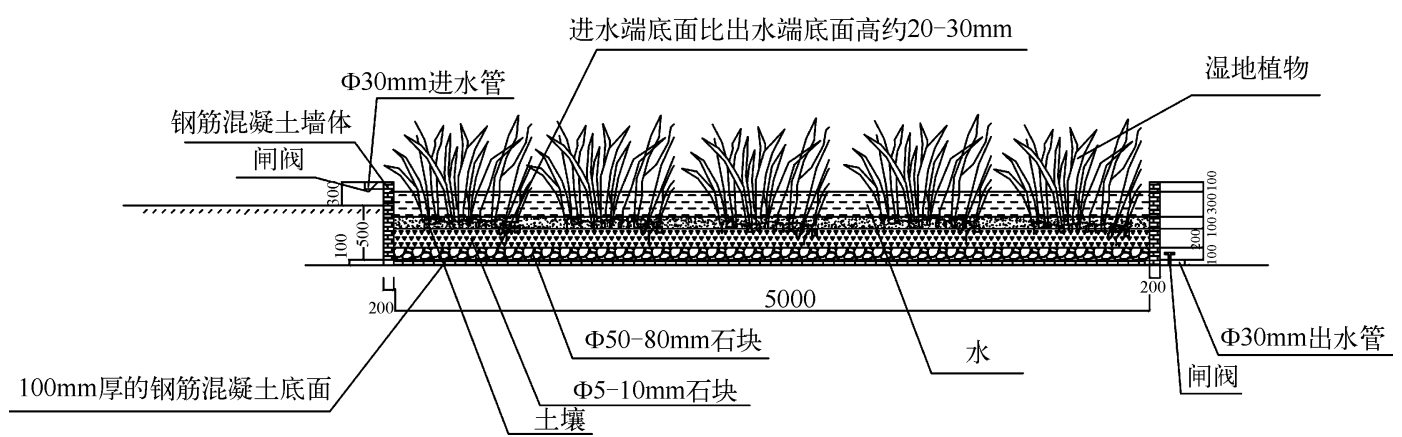

图 2 湿地植物笁池剖面图

Fig. 2 Profile of filter pool of wetland plants

\section{2 取样与测试方法}

分别于 2009 年 6 月 5 日和 2009 年 8 月 17 日进行水样采集与测试, 每个池设置三个重复. 其中, 水温和 $\mathrm{pH}$ 值采用 YSI-6820 型多参数水质监测仪现场测定. TN 浓度采用碱性过硫酸钾消解紫外分光光度法测定, 
$\mathrm{TP}$ 浓度采用钼酸铵分光光度法测定 ${ }^{[11]}$. 水深用钢卷尺测量.

2009 年 8 月 17 日, 统计每个植物篮选池中 $1 \mathrm{~m}^{2}$ 样方中植株数目、株高等生长性状, 并随机取 3 株 (水深 $10 \mathrm{~cm}$ ). 将每株样品分为地上和地下部, 在 $80^{\circ} \mathrm{C}$ 烘箱中烘至恒重后称重. 计算单株平均生物量和单位面积的 生物量. 植物样品用 $\mathrm{H}_{2} \mathrm{SO}_{4}-\mathrm{H}_{2} \mathrm{O}_{2}$ 消煮制备成溶液, 总氮用过硫酸钾氧化吸光光度法测定; 总磷用钒钼蓝法 测定 ${ }^{[12]}$.

\section{3 数据处理与分析}

$\mathrm{TN}$ 和 TP 去除率 $(R)$ 的计算公式: $R=\left(C_{0}-C_{i}\right) \times 100 / C_{0}, C_{i}$ 为第 $i$ 次 TN 或 TP 的浓度, $C_{0}$ 为 TN 或 TP 的初始浓度 ${ }^{[12]}$.

植物笁选池氮磷负荷 $(L)=$ 进水的氮磷浓度 $(I C) \times$ 进水量 $(Q)^{[12-13]}$; 植物氮磷积累量 $(P A)=$ 植物氮磷 浓度 $(P C) \times$ 植物生物量 $(P B)^{[12]}$.

采用 SPSS16.0 统计分析软件分别对 TN 和 TP 等指标因子进行单因子方差分析 (One-Way ANOVA), 并 对不同植物篮选池的污染物净化效果做多重比较 (Duncan's Multiple Range Test).

\section{2 结果与分析}

\section{1 不同湿地植物的生物量及其分配}

2009 年 5 月开始, 对栽种到植物篮选池中的 6 种植物进行观察, 了解它们的存活及生长情况. 至 2009 年 8 月 17 日,除了蒿柳生长一般以外,剩下 5 种湿地植物都生长旺盛,植株高度在 $81-184 \mathrm{~cm}$ 之间,芦苇、东 方香蒲、荠白、菖蒲、鸢尾和蒿柳的株高分别为 $184 \pm 26 、 109 \pm 6 、 173 \pm 28 、 97 \pm 26 、 81 \pm 24$ 和 $179 \pm 8 \mathrm{~cm}$.

至 2009 年 8 月 17 日, 6 种植物在植物篮选池中生一段时间以后, 各种植物的总生物量在 $424.10-$ $1772.08 \mathrm{~g} / \mathrm{m}^{2}$ 之间, 其中或尾最高, 蒿柳最低, 种间差异显著 $(P<0.05)$. 除了香蒲的地上、地下生物量比 (A/U) 达到 3.23 外,其它 5 种植物的比值在 $0.63-1.49$ 之间 (表 1). 大部分植物的地下生物量占总生物量 的 $30 \%$ 以上, 但香蒲只有 $15.47 \%$, 蒿柳则高达 $78.96 \%$. 生长在相似条件下植物篮选池中的植物, 其生物量 差异显著 $(P<0.05)$, 这应是植物内在的生长特性,也表现了物种对这种环境的适应能力.

表 1 湿地植物的生物量

Tab. 1 Biomass of wetland plants

\begin{tabular}{ccccc}
\hline 物种 & 总生物量 $\left(\mathrm{g} / \mathrm{m}^{2}\right)$ & 地上生物量 $\left(\mathrm{g} / \mathrm{m}^{2}\right)$ & 地下生物量 $\left(\mathrm{g} / \mathrm{m}^{2}\right)$ & $\mathrm{A} / \mathrm{U}$ \\
\hline 芦苇 & $430.63 \pm 48.68^{\mathrm{a}}$ & $257.11 \pm 15.22^{\mathrm{a}}$ & $173.51 \pm 33.54^{\mathrm{a}}$ & 1.49 \\
东方香蒲 & $928.01 \pm 17.94^{\mathrm{b}}$ & $708.45 \pm 50.18^{\mathrm{b}}$ & $219.56 \pm 53.46^{\mathrm{abg}}$ & 3.23 \\
萃白 & $1607.09 \pm 46.90^{\mathrm{c}}$ & $827.32 \pm 37.41^{\mathrm{c}}$ & $779.77 \pm 18.09^{\mathrm{c}}$ & 1.06 \\
菖蒲 & $1698.19 \pm 17.35^{\mathrm{d}}$ & $884.44 \pm 13.88^{\mathrm{d}}$ & $813.75 \pm 23.81^{\mathrm{cd}}$ & 1.09 \\
哥尾 & $1772.08 \pm 20.92^{\mathrm{e}}$ & $731.31 \pm 19.58^{\mathrm{be}}$ & $1040.77 \pm 1.34^{\mathrm{e}}$ & 0.70 \\
蒿柳 & $424.10 \pm 18.79^{\mathrm{af}}$ & $164.29 \pm 34.13^{\mathrm{f}}$ & $259.81 \pm 28.65^{\mathrm{gf}}$ & 0.63 \\
\hline
\end{tabular}

* 同组内同一列字母不同表示在 $5 \%$ 水平具有显著差异性.

\section{2 不同湿地植物的氮磷浓度}

2009 年 8 月 17 日, 实验植物地上部分 $\mathrm{N}$ 浓度在 $13.12-28.83 \mathrm{mg} / \mathrm{g}$ 之间, 芦苇最高, 蒿柳最低, 且各植 物之间的差异显著 $(P<0.05)$; 地上部分 $P$ 浓度以感尾最高 $(3.77 \mathrm{mg} / \mathrm{g})$, 蒿柳最低 $(1.55 \mathrm{mg} / \mathrm{g})$, 各植物之间 的差异也显著 $(P<0.05)$. 所有实验植物地下部分 $\mathrm{N}$ 和 $\mathrm{P}$ 浓度在 $7.76-15.60 \mathrm{mg} / \mathrm{g}$ 及 $1.70-2.71 \mathrm{mg} / \mathrm{g}$ 之 间,差异显著 $(P<0.05) .6$ 种植物地上部分和地下部分之间 $\mathrm{N}$ 和 $\mathrm{P}$ 的浓度差异显著 $(P<0.05), 6$ 种植物的 地上部分 $\mathrm{N}$ 浓度和 4 种植物的地上部分 $\mathrm{P}$ 浓度高于地下部分, 仅有荠白和蒿柳的地上部分 $\mathrm{P}$ 浓度低于地下 部分(图 3a).

\section{3 不同湿地植物的氮、磷积累量}

菖蒲具有最高的 N、P 积累量, 分别为 $36.46 \mathrm{~g} / \mathrm{m}^{2}$ 和 $5.00 \mathrm{~g} / \mathrm{m}^{2}$, 分别超过 6 种植物平均 N、P 积累量, 属于 高积累功能群; 蒿柳的 $N 、 P$ 积累量最低, 分别为 $4.17 \mathrm{~g} / \mathrm{m}^{2}$ 和 $0.76 \mathrm{~g} / \mathrm{m}^{2}$ (图 $3 \mathrm{~b}$ ), 属于低积累功能群. 6 种植物 
平均 N、P 积累量为 $20.60 \mathrm{~g} / \mathrm{m}^{2}$ 和 $3.08 \mathrm{~g} / \mathrm{m}^{2}$, 其中地上部分平均 $\mathrm{N} 、 P$ 积累量为 $13.72 \mathrm{~g} / \mathrm{m}^{2}$ 和 $1.89 \mathrm{~g} / \mathrm{m}^{2}$, 分别 占 $66.60 \%$ 和 $58.22 \%$, 可见实验植物的氮、磷主要积累在地上部分, 这种分配有利于通过收割地上部去除 氮、磷.

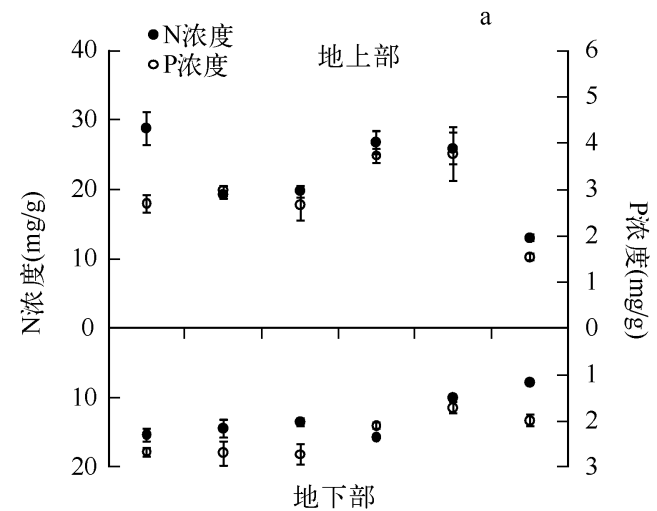

芦苇东方香蒲荠白菖蒲或尾 蒿柳

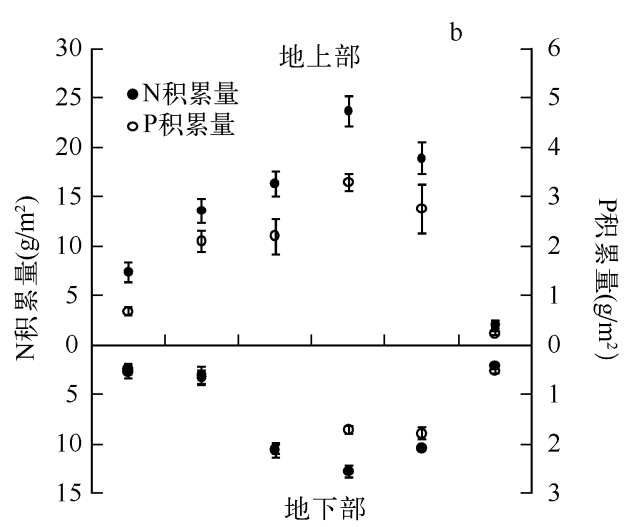

芦苇东方香蒲荠白 菖蒲或尾 蒿柳

图 36 种植物地上部和地下部的氮磷浓度 $(\mathrm{a})$ 和积累量 $(\mathrm{b})$

Fig. 3 Aboveground and underground concentrations(a) and accumulation(b) of nitrogen and phosphorus in six plants

各植物的氮磷积累量分别与生物量、各植物的氮累积量和氮浓度、磷累积量与磷浓度均呈显著的线性 关系 $(P<0.05$, 图 4), 其中氮磷积累量与生物量的相关系数分别为 0.95 和 0.98 , 氮磷积累量与氮磷浓度的 相关系数分别为 0.64 和 0.68 , 说明氮磷积累量与生物量的相关性更好. 因而可以通过生物量来评价植物对 氮磷去除的作用.
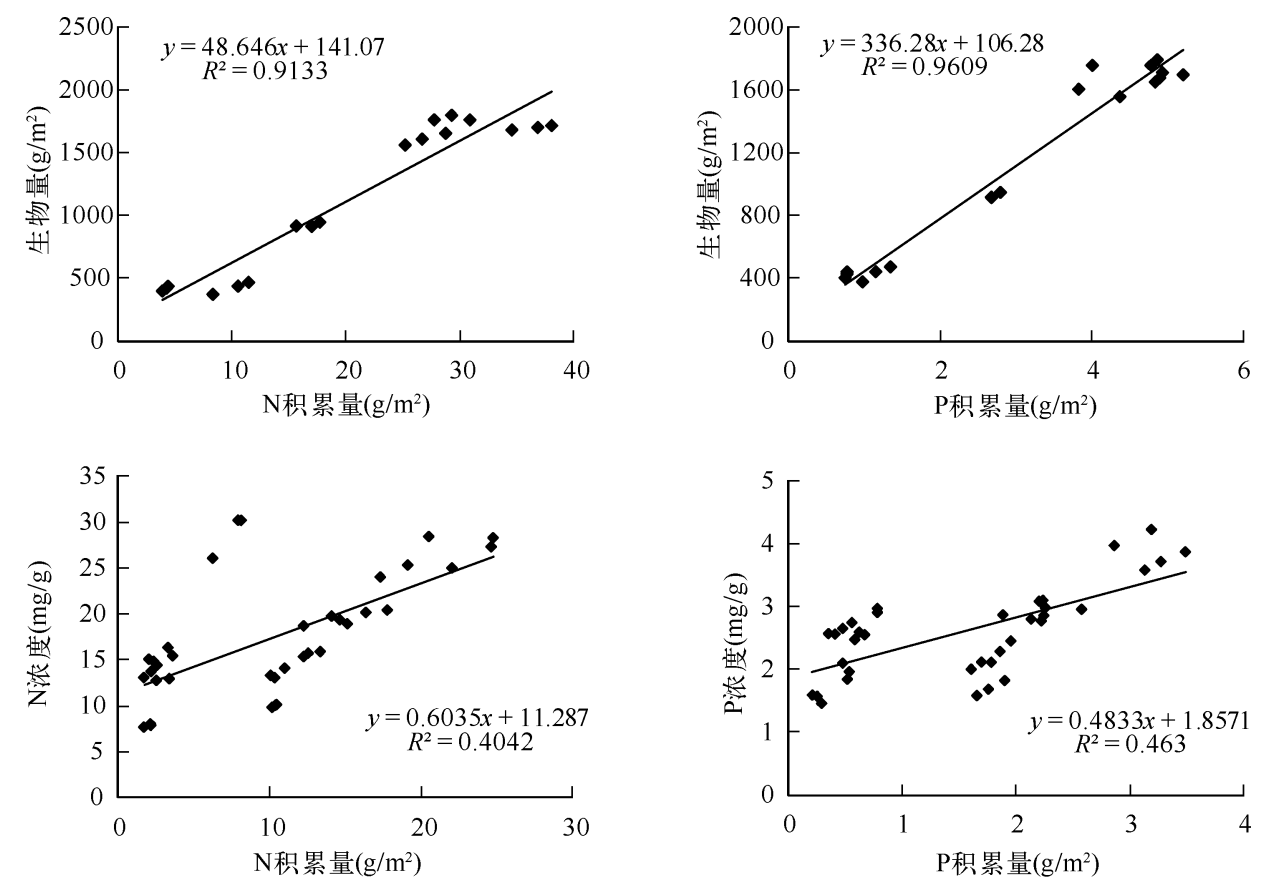

图 4 植物氮磷积累量与植物生物量、植物氮磷浓度的关系

Fig. 4 Relationship between plant nitrogen and phosphorus accumulation and biomass, plant nitrogen and phosphorus concentration 


\section{4 不同湿地植物篎选池对氮磷去除的净化效果}

不同植物篎选池对 TN 和 TP 的净化效果存在极 显著性差异 $(P<0.01)$ (表 2). 不同植物篎选池对 $\mathrm{TN}$ 的净化效果从高到低依次为或尾 $>$ 菖蒲 $>$ 芦苇 $>$ 蒿 柳 $>$ 东方香蒲 $>$ 荠白,㚜尾对 TN 的净化效果显著高 于蒿柳、东方香蒲和菱白 $(P<0.05)$, 而与菖蒲和芦 苇的净化效果差异不显著 $(P>0.05)$. 不同植物篮选 池对 TP 的净化效果从高到低依次为芦苇 $>$ 或尾 $>$ 菖 蒲 $>$ 东方香蒲 $>$ 荠白 $>$ 蒿柳, 芦苇池对 TP 的净化效 果显著高于其它 5 种植物 $(P<0.05)$.
表 2 不同湿地植物对污染物净化效果的比较*

Tab. 2 Comparison of pollutant removal efficiencies of different wetland plants

\begin{tabular}{|c|c|c|}
\hline 植物篮选池 & TN 去除率 (\%) & TP 去除率(\%) \\
\hline 芦苇池 & $87.16 \pm 4.44^{\mathrm{ag}}$ & $82.05 \pm 2.16^{\mathrm{a}}$ \\
\hline 东方香蒲池 & $82.35 \pm 0.31^{\mathrm{ab}}$ & $54.26 \pm 10.99^{\mathrm{bg}}$ \\
\hline 艾白池 & $67.00 \pm 10.02^{\circ}$ & $53.44 \pm 10.72^{\mathrm{bc}}$ \\
\hline 菖蒲池 & $87.58 \pm 1.02^{\mathrm{adg}}$ & $61.10 \pm 9.48^{\mathrm{bd}}$ \\
\hline 㚜尾池 & $91.70 \pm 0.31^{\mathrm{ge}}$ & $64.81 \pm 4.39^{\mathrm{be}}$ \\
\hline 蒿柳池 & $84.98 \pm 0.96^{\text {af }}$ & $50.61 \pm 1.55^{\text {cdgf }}$ \\
\hline
\end{tabular}

\section{3 讨论}

对于生长在相同条件下的 6 种实验植物, 其生物量及分配变化很大, 而且各植物的地上部生物量和地 下部生物量所占的比例也各不相同, 多数湿地植物的地上部生物量等于或大于地下部生物量, 就植株体内 的氮、磷含量而言, 植物的地上部氮、磷含量高于地下部 (蒿柳除外), 这应是植物内在的生长特性,也表现了 物种对环境的适应能力. 植物体内的氮、磷质量分数和积累量能够反映出该种植物对氮、磷的直接去除能力 的大小, 营养物质的分配特点将涉及到采取何种收割方式. 在本研究中, 大部分的试验物种显示植物体的 $\mathrm{N}$ 、 $P$ 积累量主要集中在植物的地上部分, 这符合 $N 、 P$ 元素主要供给营养生长部位的分配特点. 所以通过对植 物地上部分的收割, 就可以去除大部分的 N、P 积累量. 对于一些物种, 比如菖蒲, 其地下部分的 N、P 积累量 也不能忽视,应在适宜的时候进行全面收获,使其移出系统. 同时, 本研究也显示, 植物体中的 N、P 积累量主 要与植物的生物量存在线性相关, 生物量对氮、磷积累量的影响大于植物体内氮、磷浓度的影响, 所以选择 适宜在人工湿地生长的物种, 通过增加植物的生物量, 对去除 N、P 也有重要作用. 蒋跃平等的研究也显示, 生物量与氮、磷积累量的相关性优于植物体内氮、磷浓度 ${ }^{[3,14]}$. 不同植物在试验池中的生物量有较大差异,或 尾的生物量大于其他植物; 马牧源等在黄花或尾 (Iris pseudoacorus) 对富营养化水体净化的实验中发现黄花 或尾根际氮循环菌最密集, 可提高水体中硝化一反硝化作用强度,加速水体中氮的去除 ${ }^{[15]}$.

Gersberg 等 ${ }^{[16]}$ 在利用芦苇等水生植物净化城镇污水的研究中发现芦苇对氨氮的净化效果明显高于香 蒲,魏成等 ${ }^{[17]}$ 也发现芦苇对 TN 的净化效果较好, 徐德福等 ${ }^{[18]}$ 在研究不同水生植物的氮磷净化效果时发现 芦苇的生物量大,氮磷净化功能最好, 同本研究中芦苇池吸收对氮磷去除的贡献较高相似. 国内外关于蒿柳 对污染物净化效果的研究较少, 且木本植物的净化效果与植物的生长阶段有关,本研究结果表明蒿柳对磷 的净化效果低于湿地植物. 本研究所选择的植物中, 芦苇属于对氮磷具有高吸收功能、生命力强的植物种 类, 可作为北京人工湿地植物的首选目标; 蒿柳对污水中的磷净化能力相对较弱, 出于人工湿地植物多样性 原则和景观配置的需要, 蒿柳也可在人工湿地中使用. 植物对污染物的净化效果与植物的生长速度、生长阶 段、植物的生物量、植物自身氮磷累积量以及植物根际微生物作用有关 ${ }^{[12,19-21]}$. 在今后利用湿地植物净化污 水时, 要根据所处理污水的污染状况、景观需要及当地的气候特点, 结合当地的本身条件有针对性地选择合 适的湿地植物,选择适合的功能群植物, 考虑合理搭配, 最大限度地发挥湿地植物的作用.

\section{4 参考文献}

[1] 成水平,吴振斌,况琪军. 人工湿地植物研究. 湖泊科学, 2002,14(2): 179-184.

[ 2 ] Allen WC, Hook PB, Biederman JA et al. Wetlands and aquatic processes: Temperature and wetland plant species effects on wastewater treatment and root zone oxidation. Journal of Environmental Quality, 2002,31(3) :1010-1016.

[ 3 ] 蒋跃平, 暮 滢, 岳 春等. 轻度富营养化水人工湿地处理系统中植物的特性. 浙江大学学报 (理学版), 2005, 32 (3) : 309-313.

[ 4 ] 王庆海,段留生,武菊英等. 北京地区人工湿地植物活力及污染物去除能. 应用生态学报, 2008, 19(5):1131-1137.

[ 5 ] Hubbard RK, Gascho GJ, Newton GL. Use of floating vegetation to remove nutrients from swine lagoon wastewater. American Society of Agricultural Engineers, 2004,47(6) :1963-1971. 
[ 6 ] 方云英,杨肖娥,常会庆等. 利用水生植物原位修复污染水体. 应用生态学报,2008,19(2):407-412.

[ 7 ] Coleman J, Hench K, Garbutt A. Treatment of domestic wastewater by three plant species in constructed wetlands. Water Air and Soil Pollution, $2001, \mathbf{1 2 8}(3)$ :283-295.

[ 8 ] 陈源高, 吴献花, 李文朝等. 抚仙湖窑泥沟人工湿地的除磷效果研究应用. 生态学报,2005,16(10):1913-1917.

[9] 袁东海, 任全进, 高士祥等. 几种湿地植物净化生活污水 COD、总氮效果比较. 应用生态学报, 2004, 15(12): 2337-2341.

[10］韩潇源, 宋志文, 李培英. 高效净化氮磷污水的湿地水生植物耖选与组合. 湖泊科学, 2008,20(6):741-747.

[11］国家环境保护局. 水和废水监测分析方法(第四版). 北京: 中国环境科学出版社,2002,210-257.

[12] 葛 溁, 常 杰, 王晓月等. 两种程度富营养化水中不同植物生理生态特性与净化能力的关系. 生态学报,2000,20 (6) $: 1050-1055$.

[13] 孙瑞莲, 张 建, 王文兴. 8 种挺水植物对污染水体的净化效果比较. 山东大学学报 (理学版), 2009,44(1):12-16.

[14] 蒋跃平, 葛 滢, 岳春雷等. 人工湿地植物对观赏水中氮磷去除的贡献. 生态学报,2004,24(8):1720-1725.

[15] 马牧源, 王 兰,孙红文. 黄花或尾对富营养化水体净化的试验研究. 农业环境科学学报,2006,25(2):448-452.

[16] Gersberg RM, Elkins BV, Lyon SR et al. Role of aquatic plants in wastewater treatment by artificial wetlands. Water Research, 1986,20(3):363-368.

[17] 魏 成,刘 平,秦 晶. 不同基质和不同植物对人工湿地净化效率的影响. 生态学报,2008,28(8):3691-3697.

[18] 徐德福, 徐建民, 王华胜等. 湿地植物对富营养化水体中氮、磷吸收能力研究. 植物营养与肥料学报, 2005,11 (5): 597-601.

[19] Abdeslam Ennabili, Mohammed Ater, Michel Radoux. Biomass production and N P K retention in macrophytes from wetlands of the Tingitan Peninsula. Aquatic Botany, 1998 ,62:45-56.

[20］卢少勇,张彭义,余 刚等. 人工湿地处理农业径流的研究进展. 生态学报,2007,27(6):2627-2635.

[21] 王圣瑞,年跃刚,侯文华等. 人工湿地植物的选择. 湖泊科学,2004,16(1):91-96. 